\title{
T-cell co-stimulatory molecules: novel targets for the treatment of allergic
} airway disease

\author{
K.C. Beier, T. Kallinich and E. Hamelmann
}

ABSTRACT: The first two articles in this series discussed the fundamental concept of T-cell costimulation as a key event in the induction of any immune response, in addition to reviewing the current data on the role of co-stimulatory molecules for the induction and progression of allergic airway diseases. Based on these considerations, this final edition will delineate and discuss novel strategies for the prevention and/or therapy of allergic diseases based upon the modulation of costimulation.

KEYWORDS: Allergic airway disease, asthma, co-stimulation, T-cells, therapeutic targets

A llergic airway disease is characterised by reversible airway obstruction and bronchial hyperreactivity based upon allergen-induced airway inflammation. Chronic uncontrolled inflammation damages lung tissues and ultimately leads to structural changes (remodelling), thus causing irreversible loss of lung function. The overall socio-economic and healthcare burden caused by this kind of chronic airway disease is a major concern worldwide, and new methods to inhibit or suppress the chronic inflammatory process is a primary goal of asthma therapy.

Current guidelines for asthma treatment recommend first-line anti-inflammatory therapy with inhaled and, in the most severe cases, systemic corticosteroids (CS) [1]. CS are, in most cases, effective in controlling the allergic airway inflammation, but bear the risk of adverse effects, such as general or local immune suppression, diabetes, adiposity etc., due to their pleiotropic effects on various cell types and tissues. Positive long-term effects in preventing tissue remodelling by treatment with CS have been challenged by data showing little or no effect of continuous CS treatment on post-bronchodilator forced expiratory volume in one second, the parameter most closely linked to structural changes of lung tissues [2]. Furthermore, the need for continuous application of CS and the lack of a curative approach are a matter for discussion [3]. Supplementary or new anti-inflammatory drugs for asthma therapy such as antihistamines, phosphodiesterase E4 inhibitors, leukotrineantagonists or even anti-immunoglobulin (Ig)E only suppress certain symptoms or parts of the allergic inflammatory process but fail to control the complete cascade. Therefore, full or satisfying control of symptoms is barely achieved even with a combination of several of these drugs [4], and the use of general immunosuppressive agents such as cyclosporine $\mathrm{A}$ or methotrexate is sometimes the last option for patients with steroid-resistant or dependant disease. The only treatment directed at the underlying immune deviation of allergic diseases is specific immunotherapy, but it is limited by availability of only certain allergens and the risk of severe or even fatal side-effects.

Increasing insight into the underlying immune mechanisms of allergic airway inflammation gave rise to new experimental approaches interfering with the inflammatory process in a more specific and pathogenesis-related way by targeting certain cells, cytokines or cell surface molecules. Since the late 1990s it has been shown in experimental models that certain cells and

\section{AFFILIATIONS}

Dept of Paediatric Pneumology and Immunology, Charité Medical University of Berlin, Berlin, Germany.

\section{CORRESPONDENCE}

E. Hamelmann

Dept of Paediatric Pneumology and Immunology

Charite - Universitätsmedizin Berlin Campus Virchow-Klinikum Augustenburger Platz 1

13353 Berlin

Germany

Fax: 4930450566931

E-mail: eckard.hamelmann@

charite.de

Received:

July 182006

Accepted after revision:

December 292006

STATEMENT OF INTEREST

None declared. 
mediators like mast cells [5], B-cells and even IgE [6] are dispensable for the progression of the inflammatory process. For CD4+ T-cells however, there is strong and convincing evidence for an obligatory role in the development of allergic immune responses in the lung [7-9]. Activation, differentiation and effector cell function of CD4+ T-cells is directed by socalled co-stimulatory molecules that deliver critical signals modulating the antigen-specific signal of the T-cell receptor (TCR). A large number of co-stimulatory molecules have been identified since the mid 1990s, which were introduced in the first part of this series [10]. There is increasing evidence that at least some of these molecules have a pivotal role in the induction and maintenance of allergen-induced airway inflammation, as summarised in the second part of this series [11]. The current third and final part of the series will: 1) outline data from experimental studies in murine models of allergic airway inflammation interfering with co-stimulatory pathways by means of blocking reagents; 2) examine these experimental findings with regard to optimal targets for human intervention; and finally 3) discuss future intervention strategies in human allergic airway disease.

\section{TREATMENT OF ALLERGEN-INDUCED AIRWAY INFLAMMATION BY TARGETING CO-STIMULATORY MOLECULES: WHAT IS THE EXPERIMENTAL EVIDENCE?}

The role of co-stimulatory molecules in allergen-induced airway inflammation has mostly been studied in murine models. The approaches may be classified according to the time of intervention as: 1) primary intervention which targets the induction phase of the allergic sensitisation; 2) secondary prevention, targeting the induction of airway inflammation in already sensitised animals; or 3) treatment of animals after sensitisation and airway allergen challenges (table 1). In general, it is obvious from the experimental data that early blocking of allergic sensitisation effectively inhibits the development of specific IgE, cytokine production by type $2 \mathrm{~T}$-helper cells (Th2; mostly determined in bronchoalveolar lavage (BAL) fluids), airway hyperresponsiveness (AHR) and inflammation. Even though not fully applicable to human disease, animal models provide valuable insight into the processes involved and are the basis for further research in humans. Due to the lack of human studies on co-stimulatory molecules in allergic airway disease, the present discussion is based on current knowledge as gained from animal models. The most intensively studied molecules in this context are CD28, inducible costimulatory antigen (ICOS) and CD134 (OX40), which will be discussed in more detail. Only preliminary data have been obtained on other co-stimulatory pathways. Table 1 provides an overview of the current data regarding the role of costimulatory molecules in murine allergen-induced airway disease, as will be discussed.

\section{Targeting CD28}

The role of CD28 in models of allergic airway inflammation has been extensively studied in murine models of allergeninduced airway inflammation (table 1). Although the primary goal of these studies was to analyse the impact of costimulatory molecules on different aspects of the inflammatory process, e.g. eosinophilic airway inflammation, Th2 cytokine production, AHR and systemic IgE synthesis, these data can also be used to assess the suitability of CD28 as a therapeutic target in the treatment of allergic airway inflammation.

Systemic administration of the fusion protein cytotoxic Tlymphocyte antigen (CTLA)-4-Ig inhibits the ligation of CD28 with its ligands, CD80 and CD86. When given during the course of allergen sensitisation, a drastic effect on airway inflammation and AHR was observed; however, the production of the Th1 cytokine interferon (IFN)- $\gamma$ was unaltered [12, 16]. Some of these effects may be explained by the complete inhibition of the germinal centre reaction after blockade of the CD28/CD86 signal during the primary immune response [27]. When CTLA-4-IgG was applied after the initial T-cell sensitisation, i.e. during the phase of allergen rechallenge, this treatment also led to a marked reduction in the inflammatory response $[13,19,20]$. Only one report has shown contrasting results with no effect on AHR and cellular infiltration following the administration of CTLA-4-Ig at the time of allergen challenge [16]. Thus, interruption of the CD28 costimulatory signal also inhibits secondary immune responses, in at least some protocols of murine allergen-induced airway inflammation, but has the strongest impact on primary immune responses upon the first exposure to allergen.

In other studies, monoclonal antibodies against the two ligands of CD28, CD80 and CD86, were administered independently to delineate the role of these molecules. Overall analysis of these studies reveals that CD86 appears to be the major ligand responsible for CD28-dependent immune responses observed during allergen-induced airway inflammation (table 1). This is also implied by the observation that a combination of antibodies against both ligands was not superior to antiCD86 treatment alone in two out of three studies [20, 21]. The question of a differentiated role of the two CD28 ligands was further addressed by the use of a fusion protein, Y100F. This molecule blocks CD28-CD80 interactions, leaving CD28 signalling via CD86 intact [28]. Similar to CTLA-4-Ig, application of Y100F reduced eosinophilic infiltration into the lungs, mainly due to decreased interleukin (IL)- 5 production by allergen-specific T-cells [29]. In contrast to blocking all CD28 signals, Y100F had no effect on the number of eosinophils in peripheral blood or on systemic IgE production, indicating a major role of CD86 signals in local immune responses.

In somewhat different experimental settings, ligation of $\mathrm{CD} 28$ by the CD28 ligand CD80 has been shown to have either no [20-22], an increasing [28,29] or a decreasing effect [30,31] on allergen-induced airway responses. Thus, the precise role of this CD28 ligand in the T-cell differentiation remains an unanswered question.

\section{Targeting ICOS}

In contrast to blocking CD28, blockade of ICOS by the application of ICOS-Ig or anti-ICOS monoclonal antibodies $(\mathrm{mAb})$ at the time of allergen sensitisation, showed only little effect on the development of airway inflammation (table 1) [16]. However, blockade of ICOS in sensitised mice significantly reduced signs of allergic airway inflammation, such as increased IgE and Th2 cytokine production [16]. Using a model of adoptive transfer, it was further demonstrated that blockade of ICOS distinctively inhibited Th2-mediated lung eosinophilia and airway hyperreactivity, but did not abrogate Th1-mediated 


\section{TABLE 1 Murine studies blocking co-stimulatory molecules in allergen-induced airway disease}

\begin{tabular}{|c|c|c|c|c|c|c|}
\hline \multirow[t]{2}{*}{ Approach } & \multirow[t]{2}{*}{ Target } & \multicolumn{4}{|c|}{ Outcome } & \multirow[t]{2}{*}{ [Ref.] } \\
\hline & & Eosinophilia in BAL & Pulmonary infiltration & AHR & $\lg E$ & \\
\hline \multirow[t]{7}{*}{ Prevention of sensitisation } & CD80/CD86 & $\downarrow$ & ND & $\downarrow$ & $\downarrow$ & [12] \\
\hline & CD80/CD86 & ND & $\downarrow$ & $\downarrow$ & ND & [13] \\
\hline & CTLA-4 & $\uparrow$ & ND & $\uparrow$ & $\uparrow$ & [14] \\
\hline & ICOS & $(\downarrow)$ & $\leftrightarrow$ & $\leftrightarrow$ & $(\downarrow)$ & {$[16]$} \\
\hline & OX40L & $\downarrow$ & $\downarrow$ & $\downarrow$ & $\downarrow$ & {$[17]$} \\
\hline & CD30L & ND & $\downarrow$ & $\downarrow$ & $\downarrow$ & {$[18]$} \\
\hline & CD30 & ND & $\downarrow$ & $\downarrow$ & $\downarrow$ & [18] \\
\hline \multirow{10}{*}{$\begin{array}{l}\text { Prevention of airway } \\
\text { inflammation }\end{array}$} & CD80/CD86 & $\downarrow$ & $\downarrow$ & ND & $\downarrow$ & [13] \\
\hline & CD80/CD86 & $\downarrow$ & ND & $\downarrow$ & $\downarrow$ & [12] \\
\hline & CD80/CD86 & $(\downarrow)$ & ND & $\leftrightarrow$ & $\leftrightarrow$ & [22] \\
\hline & CD80/CD86 & $\downarrow$ & $\downarrow$ & ND & $\leftrightarrow$ & [23] \\
\hline & CTLA-4 & $\leftrightarrow$ & ND & $\leftrightarrow$ & $\leftrightarrow$ & {$[14]$} \\
\hline & ICOS-L & $\downarrow$ & $\downarrow$ & $\downarrow$ & ND & {$[16]$} \\
\hline & ICOS-L & $\downarrow$ & $\downarrow$ & ND & ND & [24] \\
\hline & ICOS & $\downarrow$ & $\downarrow$ & $\downarrow$ & $\downarrow$ & {$[16]$} \\
\hline & OX40L & $\leftrightarrow$ & $\leftrightarrow$ & $\leftrightarrow$ & ND & [17] \\
\hline & OX40L & $\downarrow$ & $\downarrow$ & $\downarrow$ & $\downarrow$ & [25] \\
\hline \multirow{4}{*}{$\begin{array}{l}\text { Treatment of established } \\
\text { airway inflammation }\end{array}$} & CD80/CD86 & $\downarrow$ & ND & ND & $\downarrow$ & [26] \\
\hline & ICOS & ND & $\leftrightarrow$ & ND & $\leftrightarrow$ & {$[15]$} \\
\hline & CD30 & ND & $\leftrightarrow$ & $\leftrightarrow$ & $\leftrightarrow$ & [18] \\
\hline & CD30-L & ND & $\leftrightarrow$ & $\leftrightarrow$ & $\leftrightarrow$ & {$[18]$} \\
\hline
\end{tabular}

BAL: bronchoalveolar lavage; AHR: airway hyperresponsiveness; Ig: immunoglobulin; ND: not determined; CTLA: cytotoxic T-lymphoctye antigen; ICOS: inducible co-stimulator antigen; ICOS-L; ICOS ligand; OX40: CD134; OX40L: OX40 ligand; $\downarrow$ : decreased; $\uparrow$ : increased; $(\downarrow)$ : weak increase; $\leftrightarrow$ : unchanged.

neutrophilic airway inflammation [24]. Similarly, the Th2associated airway inflammatory response to Schistosoma mansoni eggs was attenuated by ICOS blockade, whereas the priming of T-cells towards the Th2 cell direction was abolished by this approach [32]. The differential role of ICOS in Th1 versus Th2biased immune reactions was further analysed in a model of allergen-induced primary immune reactions induced by the local application of Th1 and Th2 cytokines. In this model, blockade of ICOS inhibited the early inflammatory cell influx and IL-5 production in the lungs in the Th2, but not in the Th1, model [15].

Taken together these results render ICOS a promising target to interfere with secondary immune responses, and suggest a predominant involvement of ICOS in Th2-type responses.

\section{Targeting OX40}

Utilising OX40 knock-out mice, it was demonstrated that OX40 plays an important role in effector cell expansion and the formation and re-activation of memory T-cells [33-36]. Blocking the OX40 signal with mAb against OX40L in a model of Leishmania major infection resulted in decreased synthesis of Th2 cytokines (IL-4, IL-10 and IL-13) as well as reduced production of $\operatorname{IgE}$ [37]. In mouse models of allergen-induced airway inflammation there are somewhat controversial results regarding the time-point of OX40 action. Blockade of OX40L abolished the development of airway inflammation only when the anti-OX40L mAb was applied during allergen sensitisation, but not when given to already sensitised mice prior to allergen airway challenge [17]. In contrast, another study demonstrated that OX40L blockade of sensitised mice during allergen airway challenges abolished inflammatory responses, also at very late time points of the experimental protocol [25].

\section{Other co-stimulatory pathways}

Very limited information is available on the effects of blocking other co-stimulatory molecules in murine models of allergeninduced airway disease. To date, no studies investigating the blockade of the B- and T-lymphocyte attenuator (BTLA) or B7$\mathrm{H} 3$ have been published. Recently, it was shown that a single injection of $\mathrm{mAb}$ against the co-stimulatory factor CD137 (41BB) prevented the development of AHR, eosinophilic airway inflammation and elevated IgE production [38]. This treatment was also able to reverse previously established airway disease. The inhibitory effect was most likely due to reduced Th2 cytokine production and increased secretion of IFN- $\gamma$ by CD8+ T-cells. 
Only preliminary data exist on manipulation of the negative regulatory molecule programmed cell death (PD)-1: an analysis of the distinctive contribution of its two ligands, PDL1 and PD-L2, in the development of allergen-induced murine airway inflammation showed that a substantial number of pulmonary dendritic cells (DCs), macrophages and B-cells isolated from the lungs of naïve mice expressed PD-L1, which was further enhanced after allergen sensitisation and airway challenge [39]. In contrast, PD-L2 expression was detectable at very low levels in lymphocytes of unchallenged mice, and was only moderately enhanced in DCs and macrophages after allergen challenge of sensitised mice. Although PD-L1 was abundantly expressed on various antigen-presenting cells in the inflamed lung tissues, treatment with a blocking antibody did not alter the allergic airway response, whereas treatment with anti-PD-L2 mAb (TY25) during allergen challenge significantly increased the development of airway hyperreactivity, and lung eosinophilia increased levels of IL-5 and IL-13 in BAL fluid [40]. When PD-L2 was only blocked during sensitisation, no effect on the inflammatory response was demonstrated, indicating that the inhibitory function of PD-L2 was limited to the effector phase (airway challenge) of the airway response.

Recently, blockade of CD30 and its ligand CD153 with mAbs was shown to significantly reduce airway inflammation, AHR and the production of allergen-specific IgE when the blocking antibody was administered before and after sensitisation [18]. However, neither blocking reagent had any effect when administered during established allergic airway disease.

\section{WHAT MAKES A PROMISING TARGET?}

From these studies in murine models of allergen-mediated airway inflammation, as well as from experiences of other immune modulators in asthmatic patients, some baseline conclusions may be drawn that characterise specific costimulatory molecules as optimal targets for therapeutic intervention (table 2).

\section{T-cell specificity}

When targeting T-cells, T-cell specificity is a major criterion, as simultaneous expression of the target molecule on anything other than T-cells may lead to unforeseen side-effects. An example of this was experienced in early clinical trials blocking the CD40 ligand (CD40L) with mAbs. Blocking of CD40L in murine models was shown to attenuate IgE production [41], although it had no effect on cellular infiltration of the airways. In patients, a monoclonal antibody directed against CD40L (Ruplizumab) was first used for the treatment of systemic lupus erythematosus. However, the trials had to be discontinued because of life-threatening pro-thrombotic side-effects due to expression of CD40L on activated platelets [42]. Therefore, T-cell restricted expression should be considered critical when identifying targets with which to modulate T-cell function. To date, this criterion is not met by the co-stimulatory molecules CD27, CD30, BTLA and PD-1.

\section{Expression on T-cells}

Targeting a molecule that is expressed constitutively on T-cells implies targeting all T-cells unselectively. Nonselective depletion of T-cells bears the risk of long-lasting lymphopenia and immune suppression, as experienced in clinical trials using anti-CD3 mAbs for immune suppression after organ transplantation [43]. Nonselective and strong stimulation of all Tcells via a constitutively expressed co-stimulatory molecule can lead to cytokine release syndrome as seen recently with the anti-CD28 antibody TGN1412 [44]. As these are unacceptable side effects in the treatment of allergic inflammation, the constitutively expressed co-stimulatory molecules CD27, CD28, BTLA and herpes virus entry mediator do not qualify as optimal targets.

\section{Predominant involvement in secondary immune reactions}

In patients with bronchial asthma, allergic airway disease is an ongoing secondary immune response triggered by re-exposure to specific allergens. A therapeutic intervention against asthma would preferably interfere with these secondary inflammatory reactions, while leaving primary immune reactions critical in mounting a host defence against pathogens unaffected. CD28, for instance, is the major co-stimulatory factor for the activation of naïve T-cells, and is therefore critical for the initiation of primary immune responses [27]. In murine models, CD28 blockade was most effective when administered during allergen sensitisation $[12,16]$. This would render CD28 blockade an improper treatment strategy for human allergies, since the time-point of sensitisation is impossible to determine in the course of human allergic disease. However, blocking CD28 during secondary immune responses has shown some anti-inflammatory effects in mice $[19,20]$. Moreover, clinical trials for the treatment of rheumatoid arthritis, employing the blockade of the CD28/B7 pathway with a CTLA-4-Ig fusion

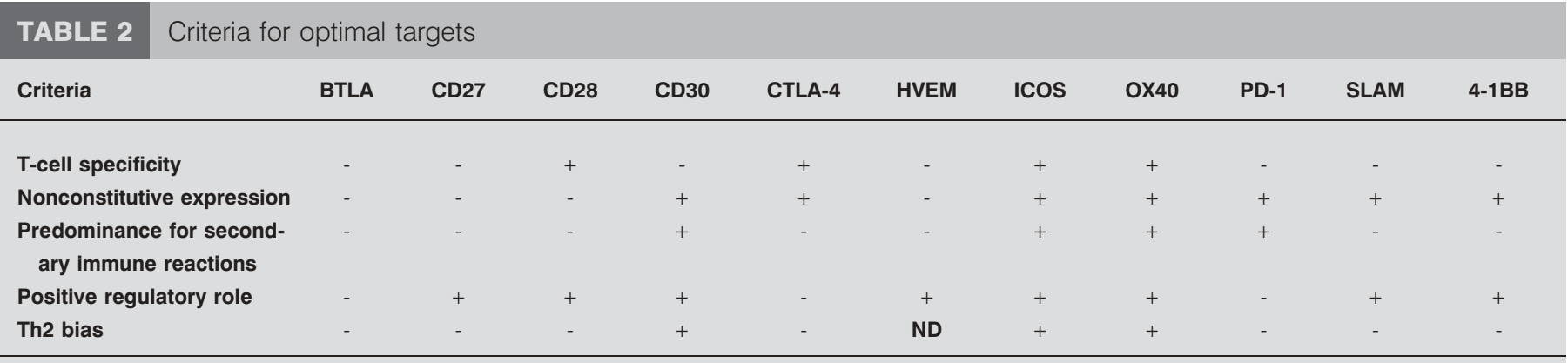

BTLA: B- and T-lymphocyte attenuator; CTLA: cytotoxic T-lymphocyte antigen; HVEM: herpes virus entry mediator; ICOS: inducible co-stimulatory antigen; OX40: CD134; PD: programmed cell death; SLAM: signalling lymphocyte activation molecule; Th2: type 2 T-helper cell; ND: not determined. 
protein, have shown little apparent toxicity and good antiinflammatory properties [45-47]. In fact, this CTLA-4-Ig fusion protein, abatacept, is the first approved anti-co-stimulatory drug on the market [48].

Two co-stimulatory molecules predominantly involved in secondary immune reactions are ICOS and OX40. In contrast to CD28, ICOS expression is limited to currently activated Tcells $[49,50]$. In murine studies, ICOS-blocking reagents were most effective during secondary immune responses [16, 32] Targeting OX40 in animal models of allergic airway disease was revealed to be effective during sensitisation, as well as during rechallenge with allergen [25].

\section{Positive regulatory signal}

One major concern, besides compromising primary physiological immune reactions, is that negative signals delivered by co-stimulatory molecules would also be compromised by this approach. Blocking negative signals bears the risk of autoreactive immune responses and increased development of autoimmune diseases as a consequence of a disrupted negative feedback mechanism of immune balance. Therefore, this may disqualify negative co-stimulatory factors, such as BTLA and CTLA-4, as optimal treatment targets.

\section{Th2 bias}

As outlined in the second part of the series [11], the allergic airway inflammation is a Th2-dominated process, although recently, evidence for the involvement of Th1 cytokines, especially in established airway disease, has arisen. The predominant involvement of Th2-cytokines in airway inflammation makes these molecules a preferable target in the therapy of allergic reaction. This criterion is only met by the costimulatory molecules CD30, ICOS and OX40. CD30, however, does not meet the criteria of T-cell specificity. ICOS is expressed on Th1 as well as on Th2 T-cells, but only Th2-mediated airway inflammation is affected by ICOS-blockade $[15,24]$.

However, during an established inflammatory response like allergic asthma, this situation might be more complex than it appears in murine models of acute airway inflammation. ICOS is also expressed on regulatory T-cells ( $\mathrm{Tr}$ ) and may be important for the production of the immune suppressive cytokine, IL-10 [51]. Even though a further study using a murine colitis model demonstrated that ICOS blockade had minimal effect on $\mathrm{Tr}$ function [52], it remains to be determined how the immune balance is affected by long-term blockade of ICOS. A complete lack of ICOS expression in humans is associated with a loss of B-cell memory [53], a side-effect that may be desirable concerning local memory for $\mathrm{IgE}$, but is definitely intolerable for any other systemic immune response. Therefore, the route of application and the place of deposition are important factors that need to be considered when targeting co-stimulatory molecules.

\section{WHAT ARE THE BEST STRATEGIES FOR INTERFERING WITH CO-STIMULATORY SIGNALS?}

Not only is the identification of the optimal target molecule a prerequisite for effective treatment by interfering with costimulatory molecules, but also careful considerations need to be made about the tools, administration and the immunological aim of successful intervention into an ongoing inflammatory process.

\section{Tools for modulation of co-stimulatory signals}

Blocking co-stimulatory signals can either be achieved using $\mathrm{mAbs}$ or fusion proteins containing the counter receptor. Halflife and tissue distribution of the blocking reagent within the human body are critical variables that will determine the duration of the blocking effect and the frequency required for application. The first insights in the human system have been gained by the use of anti-CD3 mAbs in organ transplantation [43] and the CTLA-4 fusion protein for rheumatoid arthritis [45]. Data from these and other studies show that using humanised mAbs is, in general, safe and does not bear the risk of anaphylactic side-effects. Due to the complexity of the allergic immune-response and the asthmatic airway-response it is highly likely that targeting a single molecule may not be sufficient to gain complete control of allergen-mediated inflammation. For murine models of allograft rejection, it was shown that dual blockade with mAbs was more effective than blockade of a single molecule [54]. In this respect, a feasible approach may be to target not only one, but two (e.g. ICOS and OX40) or even more co-stimulatory molecules to treat asthma (fig. 1). However, such studies are still outstanding for allergic disease models.

The consequences of using agonistic mAbs may be far more difficult to predict than those with blocking reagents. While dosing antagonists is stoichiometric, the action of agonists is a function of the strength of the agonist, the cascade it induces and the consequences of that cascade [55]. In-depth knowledge of receptor distribution and action, as well as intensive animal testing, are critical, as demonstrated by the TeGenero fiasco with an agonistic anti-CD28 antibody [44].

\section{Administration of immune modulators}

Besides systemic administration of an immune modulator, local deposition of a blocking reagent in the lungs should be considered a feasible route of application. During allergic airway inflammation, the number of T-cells producing Th2cytokines are increased in the pulmonary compartment [56]. Therefore, it seems reasonable to directly target this process in the lung to avoid systemic side-effects. Indeed, in mouse models of allergen-induced airway disease, local application of $\mathrm{mAbs}$ or fusion proteins into the airways was shown to control allergic airway inflammation, as demonstrated for the IL-13 receptor $\alpha$ fusion protein [57] and anti-IL5 mAbs [6, 58]. In humans, one study showed that administration of an inhaled monoclonal anti-IgE antibody (E25) was generally well tolerated and led to detectable levels of the antibody in both BAL and serum [59]. However, the aerosolised antibody did not attenuate the airway response to inhaled allergen as it did when applied i.v. The authors speculated that the aerosol route of application did not lead to sufficient concentrations of the antibody in the critical tissue compartments surrounding $\operatorname{IgE}$ effector cells. Furthermore, one subject developed IgG and IgA antibodies against E25, suggesting that lung deposition of the antibody may be more immunogenic than the parental route. Therefore, local deposition, tissue penetration, serum levels and half life, as well as immunogenicity, are critical variables 


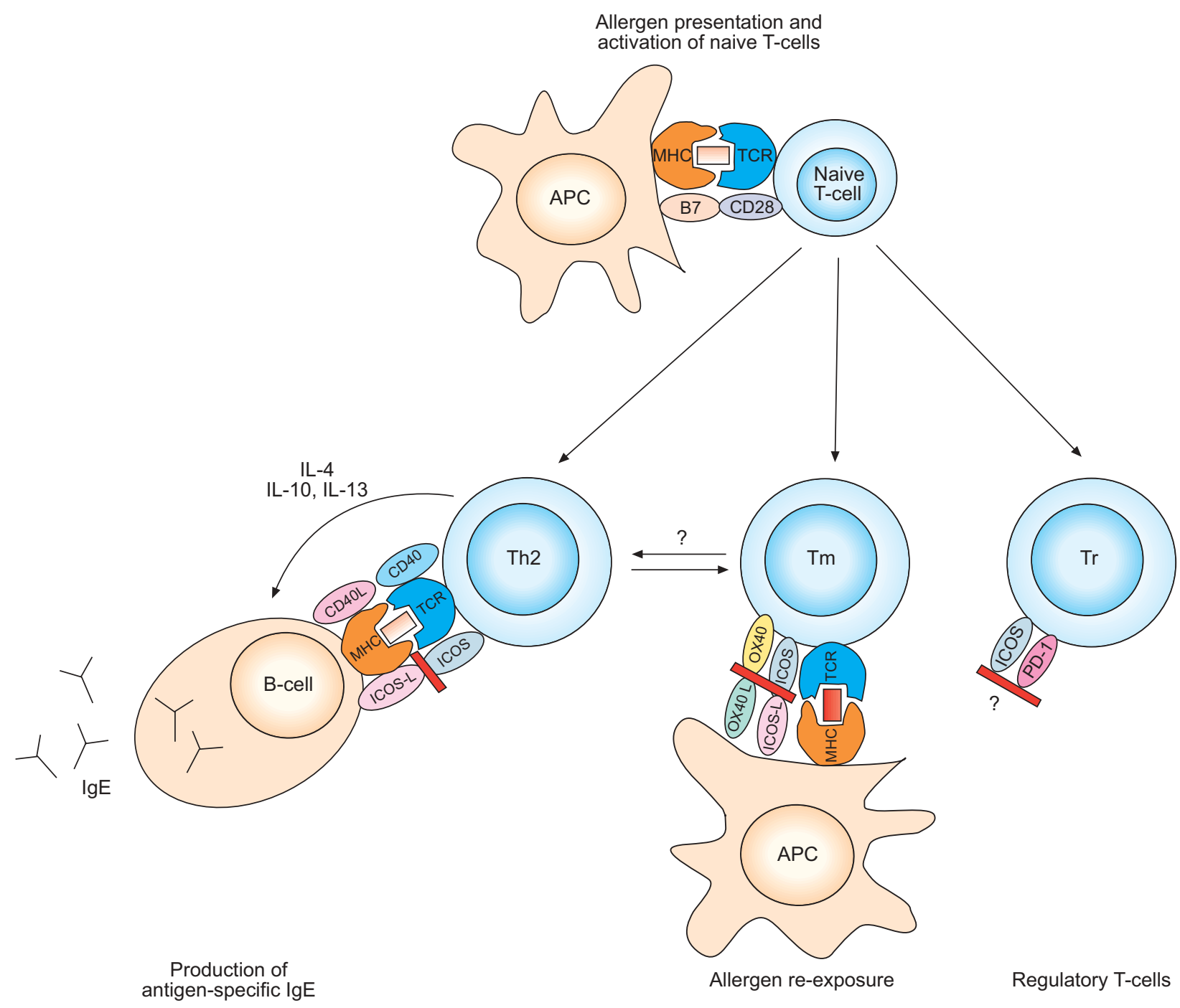

FIGURE 1. Blockade of co-stimulatory molecules in allergic airway inflammation. APC: antigen-presenting cell; MHC: major histocompatibility complex; TCR: T-cell receptor; L: interleukin; Th: T-helper cell; Tm: memory T-cell; Tr: regulatory T-cell; CD40L: CD40 ligand; ICOS: inducible co-stimulatory antigen; ICOS-L: ICOS ligand; OX40: CD134; OX40L; OX40 ligand; PD: programmed cell death; Ig: immunoglobulin.

that need to be considered when evaluating this route of application.

\section{Blockade versus elimination of allergen-specific T-cells}

An interesting alternative to continuous application of a blocking agent would be the permanent elimination of allergen-specific T-cells from the immune system, as recently proposed by KROCZEK and HAMELMANN [60]. This would require a target that is T-cell specific and not expressed on naïve or quiescent memory T-cells, but rather is expressed on recently activated T-effector or reactivated memory cells. From the group of co-stimulatory molecules, ICOS and OX40 meet these criteria. Elimination of all ICOS- and OX40-positive Tcells during an ongoing allergic reaction may remove the allergen-specific T-effector and reactivated memory T-cells, subsequently leading to downregulation of humoral responses and inflammatory cell infiltration, which both depend on T-cell help. The aspired benefits of such an approach would be a long-lasting therapeutic effect achieved by only a short-term treatment. Furthermore, this sort of treatment would be available and effective for allergic sensitisation against all possible allergens, in contrast to specific immunotherapy. However, the feasibility of this approach remains to be tested in appropriate animal models.

\section{CONCLUSION}

The underlying immune mechanisms of allergic airway disease have been untangled via the use of mouse models and clinical studies. The time has now come to widen the repertoire of therapeutic tools and to initiate immunological and pathogenesis-related approaches to treatment. One of the most promising new strategies is based on the blockade of co-stimulation, a critical and early event in the induction and maintenance of allergen-induced airway diseases such as bronchial asthma. The hypothetical concept is valid, but still needs to be tested in further experimental models and initial clinical trials. It will, however, be 
fascinating to find out which of these predictions can be turned into feasible therapeutic interventions for the future.

\section{REFERENCES}

1 Global Initiative for Asthma. Global Strategy for Asthma Management and Prevention, NHLBI/WHO Workshop report. Publication No. 02-3659. NIH Bethseda, National Institute of Health, National Heart, Lung and Blood Institute, 2002.

2 Long-term effects of budesonide or nedocromil in children with asthma. The Childhood Asthma Management Program Research Group. N Engl J Med 2000; 343: 1054-1063.

3 Hamelmann E, Schleimer RP. Corticosteroid treatment in bronchial asthma: for better or for worse? J Allergy Clin Immunol 2003; 111: 248-250.

4 Bateman ED, Boushey HA, Bousquet J, et al. Can guidelinedefined asthma control be achieved? The Gaining Optimal Asthma ControL study. Am J Respir Crit Care Med 2004; 170: 836-844.

5 Takeda K, Hamelmann E, Joetham A, et al. Development of eosinophilic airway inflammation and airway hyperresponsiveness in mast-cell-deficient mice. J Exp Med 1997; 186: 449-454.

6 Hamelmann E, Takeda K, Schwarze J, Vella AT, Irvin CG, Gelfand EW. Development of eosinophilic airway inflammation and airway hyperresponsiveness requires interleukin-5 but not immunoglobulin E or B lymphocytes. Am J Respir Cell Mol Biol 1999; 21: 480-489.

7 Azzawi M, Bradley B, Jeffery PK, et al. Identification of activated $\mathrm{T}$ lymphocytes and eosinophils in bronchial biopsies in stable atopic asthma. Am Rev Respir Dis 1990; 142: 1407-1413.

8 Gavett SH, Chen X, Finkelman F, Wills-Karp M. Depletion of murine CD4+ T lymphocytes prevents antigen-induced airway hyperreactivity and pulmonary eosinophilia. Am J Respir Cell Mol Biol 1994; 10: 587-593.

9 Maddox L, Schwartz DA. The pathophysiology of asthma. Annu Rev Med 2002; 53: 477-498.

10 Beier KC, Kallinch T, Hammelman E. Master switches of Tcell activation, differentiation. Eur Respir J 2007; 29: 804-812.

11 Kallinich T, Beier KC, Stock P, Hamelmann E. T-cell costimulatory molecules their role in allergic immune reactions. Eur Respir J 2007; 29: 1246-1255.

12 Keane-Myers A, Gause WC, Linsley PS, Chen SI, WillsKarp M. B7-CD28/CTLA-4 costimulatory pathways are required for the development of $\mathrm{T}$ helper cell 2-mediated allergic airway responses to inhaled antigens. I Immunol 1997; 158: 2042-2049.

13 Krinzman SJ, De Sanctis GT, Cernadas M, et al. Inhibition of T-cell costimulation abrogates airway hyperresponsiveness in a murine model. J Clin Invest 1996; 98: 2693-2699.

14 Hellings PW, Vandenberghe $\mathrm{P}$, Kasran A, et al. Blockade of CTLA-4 enhances allergic sensitization and eosinophilic airway inflammation in genetically predisposed mice. Eur J Immunol 2002; 32: 585-594.

15 Wiley RE, Goncharova S, Shea T, Johnson JR, Coyle AJ, Jordana M. Evaluation of inducible costimulator/B7related protein- 1 as a therapeutic target in a murine model of allergic airway inflammation. Am J Respir Cell Mol Biol 2003; 28: 722-730.
16 Gonzalo JA, Tian J, Delaney T, et al. ICOS is critical for T helper cell-mediated lung mucosal inflammatory responses. Nat Immunol 2001; 2: 597-604.

17 Hoshino A, Tanaka Y, Akiba H, et al. Critical role for OX40 ligand in the development of pathogenic Th2 cells in a murine model of asthma. Eur I Immunol 2003; 33: 861-869.

18 Polte T, Behrendt AK, Hansen G. Direct evidence for a critical role of CD30 in the development of allergic asthma. J Allergy Clin Immunol 2006; 118: 942-948.

19 Van Oosterhout AJ, Hofstra CL, Shields R, et al. Murine CTLA4-IgG treatment inhibits airway eosinophilia and hyperresponsiveness and attenuates $\operatorname{IgE}$ upregulation in a murine model of allergic asthma. Am J Respir Cell Mol Biol 1997; 17: 386-392.

20 Tsuyuki S, Tsuyuki J, Einsle K, Kopf M, Coyle AJ. Costimulation through B7-2 (CD86) is required for the induction of a lung mucosal $\mathrm{T}$ helper cell 2 (TH2) immune response and altered airway responsiveness. J Exp Med 1997; 185: 1671-1679.

21 Keane-Myers AM, Gause WC, Finkelman FD, Xhou XD, Wills-Karp M. Development of murine allergic asthma is dependent upon B7-2 costimulation. J Immunol 1998; 160: 1036-1043.

22 Haczku A, Takeda K, Redai I, et al. Anti-CD86 (B7.2) treatment abolishes allergic airway hyperresponsiveness in mice. Am J Respir Crit Care Med 1999; 159: 1638-1643.

23 Mathur M, Herrmann K, Qin Y, et al. CD28 interactions with either CD80 or CD86 are sufficient to induce allergic airway inflammation in mice. Am J Respir Cell Mol Biol 1999; 21: 498-509.

24 Coyle AJ, Lehar S, Lloyd C, et al. The CD28-related molecule ICOS is required for effective T-cell-dependent immune responses. Immunity 2000; 13: 95-105.

25 Salek-Ardakani S, Song J, Halteman BS, et al. OX40 (CD134) controls memory T helper 2 cells that drive lung inflammation. J Exp Med 2003; 198: 315-324.

26 Deurloo DT, van Esch BC, Hofstra CL, Nijkamp FP, Van Oosterhout AJ. CTLA4-IgG reverses asthma manifestations in a mild but not in a more "severe" ongoing murine model. Am J Respir Cell Mol Biol 2001; 25: 751-760.

27 Han S, Hathcock K, Zheng B, Kepler TB, Hodes R, Kelsoe G. Cellular interaction in germinal centers. Roles of CD40 ligand and B7-2 in established germinal centers. I Immunol 1995; 155: 556-567.

28 Harris N, Peach R, Naemura J, Linsley PS, Le Gros G, Ronchese F. CD80 costimulation is essential for the induction of airway eosinophilia. J Exp Med 1997; 185: 177-182.

29 Harris NL, Peach RJ, Ronchese F. CTLA4-Ig inhibits optimal $\mathrm{T}$ helper 2 cell development but not protective immunity or memory response to Nippostrongylus brasiliensis. Eur J Immunol 1999; 29: 311-316.

30 Kuchroo VK, Das MP, Brown JA, et al. B7-1 and B7-2 costimulatory molecules activate differentially the Th1/ Th2 developmental pathways: application to autoimmune disease therapy. Cell 1995; 80: 707-718.

31 Lenschow DJ, Herold KC, Rhee L, et al. CD28/B7 regulation of Th1 and Th2 subsets in the development of autoimmune diabetes. Immunity 1996; 5: 285-293.

32 Tesciuba AG, Subudhi S, Rother RP, et al. Inducible costimulator regulates Th2-mediated inflammation, but 
not Th2 differentiation, in a model of allergic airway disease. J Immunol 2001; 167: 1996-2003.

33 Gramaglia I, Weinberg AD, Lemon M, Croft M. Ox-40 ligand: a potent costimulatory molecule for sustaining primary CD4 T-cell responses. J Immunol 1998; 161: 6510-6517.

34 Gramaglia I, Jember A, Pippig SD, Weinberg AD, Killeen N, Croft M. The OX40 costimulatory receptor determines the development of CD4 memory by regulating primary clonal expansion. J Immunol 2000; 165: 3043-3050.

35 Jember AG, Zuberi R, Liu FT, Croft M. Development of allergic inflammation in a murine model of asthma is dependent on the costimulatory receptor OX40. J Exp Med 2001; 193: 387-392.

36 Arestides RS, He H, Westlake RM, et al. Costimulatory molecule OX40L is critical for both Th1 and Th2 responses in allergic inflammation. Eur J Immunol 2002; 32: 2874-2880.

37 Akiba H, Miyahira Y, Atsuta M, et al. Critical contribution of OX40 ligand to $\mathrm{T}$ helper cell type 2 differentiation in experimental leishmaniasis. J Exp Med 2000; 191: 375-380.

38 Polte T, Foell J, Werner C, et al. CD137-mediated immunotherapy for allergic asthma. J Clin Invest 2006; 116: 1025-1036.

39 Matsumoto K, Inoue H, Nakano T, et al. B7-DC regulates asthmatic response by an IFN-gamma-dependent mechanism. J Immunol 2004; 172: 2530-2541.

40 Oflazoglu E, Swart DA, Anders-Bartholo P, et al. Paradoxical role of programmed death-1 ligand 2 in Th2 immune responses in vitro and in a mouse asthma model in vivo. Eur J Immunol 2004; 34: 3326-3336.

41 Hogan SP, Mould A, Kikutani H, Ramsay AJ, Foster PS. Aeroallergen-induced eosinophilic inflammation, lung damage, and airways hyperreactivity in mice can occur independently of IL-4 and allergen-specific immunoglobulins. J Clin Invest 1997; 99: 1329-1339.

42 Kawai T, Andrews D, Colvin RB, Sachs DH, Cosimi AB. Thromboembolic complications after treatment with monoclonal antibody against CD40 ligand. Nat Med 2000; 6: 114

43 Hesse UJ, Wienand P, Baldamus C, Pollok M, Pichlmaier H. The risk of infection following OKT3 and antilymphocyte globulin treatment for renal transplant rejection: results of a single center prospectively randomized trial. Transpl Int 1992; 5: Suppl. 1, S440-S443.

44 Suntharalingam G, Perry MR, Ward S, et al. Cytokine storm in a phase 1 trial of the anti-CD28 monoclonal antibody TGN1412. N Engl J Med 2006; 355: 1018-1028.

45 Kremer JM, Westhovens R, Leon M, et al. Treatment of rheumatoid arthritis by selective inhibition of T-cell activation with fusion protein CTLA4Ig. N Engl J Med 2003; 349: 1907-1915.

46 Abrams JR, Kelley SL, Hayes E, et al. Blockade of $\mathrm{T}$ lymphocyte costimulation with cytotoxic T lymphocyteassociated antigen 4-immunoglobulin (CTLA4Ig) reverses the cellular pathology of psoriatic plaques, including the activation of keratinocytes, dendritic cells, and endothelial cells. J Exp Med 2000; 192: 681-694.

47 Moreland LW, Alten R, Van den Bosch F, et al. Costimulatory blockade in patients with rheumatoid arthritis: a pilot, dose-finding, double-blind, placebocontrolled clinical trial evaluating CTLA-4Ig and LEA29Y eighty-five days after the first infusion. Arthritis Rheum 2002; 46: 1470-1479.

48 Bluestone JA, St Clair EW, Turka LA. CTLA4Ig: bridging the basic immunology with clinical application. Immunity 2006; 24: 233-238.

49 Hutloff A, Dittrich AM, Beier KC, et al. ICOS is an inducible T-cell co-stimulator structurally and functionally related to CD28. Nature 1999; 397: 263-266.

50 Yoshinaga SK, Whoriskey JS, Khare SD, et al. T-cell costimulation through B7RP-1 and ICOS. Nature 1999; 402: 827-832.

51 Akbari O, Freeman GJ, Meyer EH, et al. Antigen-specific regulatory T-cells develop via the ICOS-ICOS-ligand pathway and inhibit allergen-induced airway hyperreactivity. Nat Med 2002; 8: 1024-1032.

52 de Jong YP, Rietdijk ST, Faubion WA, et al. Blocking inducible co-stimulator in the absence of CD28 impairs Th1 and CD25+ regulatory T-cells in murine colitis. Int Immunol 2004; 16: 205-213.

53 Grimbacher B, Hutloff A, Schlesier M, et al. Homozygous loss of ICOS is associated with adult-onset common variable immunodeficiency. Nat Immunol 2003; 4: 261-268.

54 Larsen CP, Elwood ET, Alexander DZ, et al. Long-term acceptance of skin and cardiac allografts after blocking CD40 and CD28 pathways. Nature 1996; 381: 434-438.

55 Sheridan C. TeGenero fiasco prompts regulatory rethink. Nat Biotechnol 2006; 24: 475-476.

56 Robinson DS, Bentley AM, Hartnell A, Kay AB, Durham SR. Activated memory T helper cells in bronchoalveolar lavage fluid from patients with atopic asthma: relation to asthma symptoms, lung function, and bronchial responsiveness. Thorax 1993; 48: 26-32.

57 Grunig G, Warnock M, Wakil AE, et al. Requirement for IL13 independently of IL-4 in experimental asthma. Science 1998; 282: 2261-2263.

58 Shardonofsky FR, Venzor J 3rd, Barrios R, Leong KP, Huston DP. Therapeutic efficacy of an anti-IL-5 monoclonal antibody delivered into the respiratory tract in a murine model of asthma. J Allergy Clin Immunol 1999; 104: 215-221.

59 Fahy JV, Cockcroft DW, Boulet LP, et al. Effect of aerosolized anti-IgE (E25) on airway responses to inhaled allergen in asthmatic subjects. Am J Respir Crit Care Med 1999; 160: 1023-1027.

60 Kroczek R, Hamelmann E. T-cell costimulatory molecules: optimal targets for the treatment of allergic airway disease with monoclonal antibodies. J Allergy Clin Immunol 2005; 116: 906-909. 